\title{
On Fuzzy Subgroup and Fuzzy Cosets
}

\author{
B. O. Onasanya \\ Doctoral Student \\ Department of Mathematics \\ University of Ibadan
}

\author{
S. A. llori \\ Professor \\ Department of Mathematics \\ University of Ibadan
}

\begin{abstract}
In this paper, proofs of some theorems relating to fuzzy subgroups, pseudo fuzzy cosets and pseudo fuzzy double cosets have been provided. Some new theorems are also stated and proved.
\end{abstract}

\section{Keywords:}

Some important words are fuzzy subset, fuzzy subgroup of a group, fuzzy cosets, pseudo fuzzy cosets, pseudo fuzzy double cosets and fuzzy partition.

\section{(AMS 2010 SUBJECT CLASSIFICATION 20N25)}

\section{INTRODUCTION}

Researches are becoming enormously growing in the theory and the application of fuzzy theories particularly in science of logics and engineering. Following the foundational work of Lofti A. Zadeh who introduced fuzzy subset theory as another way of studying set which are not crisp, so many other works have been done. There is the use of fuzzy to be precise, in electrical engineering and others. R. Nagarajan and A. Solairaju [4] have done some foundational works in this area but here we have some alternative and/or even independent proofs of some of their works.

\subsection{Preliminaries}

Definition 1.1.1: Let $\mathrm{X}$ be a non-empty set. A fuzzy subset $\mu$ of the set $\mathrm{G}$ is a function $\mu: \mathrm{G} \rightarrow[0,1]$.

Definition 1.1.2: Let $\mathrm{G}$ be a group and $\mu$ a fuzzy subset of $\mathrm{G}$. Then $\mu$ is called a fuzzy subgroup of $\mathrm{G}$ if

$$
\begin{array}{ll}
\text { (i) } & \mu(\mathrm{xy}) \geq \min \{\mu(\mathrm{x}), \mu(\mathrm{y})\} \\
\text { (ii) } & \mu\left(\mathrm{x}^{-1}\right)=\mu(\mathrm{x}) \\
\text { (iii) } & \mu \text { is called a fuzzy normal subgroup if } \\
& \mu(\mathrm{xy})=\mu(\mathrm{y} x) \text { for all } \mathrm{x} \text { and } \mathrm{y} \text { in } \mathrm{G}
\end{array}
$$

Definition 1.1.3: Let $\mu$ be a fuzzy subgroup of a group G. For $\mathrm{a}$ in $\mathrm{G}$, the fuzzy coset $a \mu$ of $\mathrm{G}$ is defined by $(\mathrm{a} \mu)(\mathrm{x})=\mu\left(\mathrm{a}^{-1} \mathrm{x}\right)$ for all $\mathrm{x}$ in $\mathrm{G}$.

Definition 1.1.4: Let $\mu$ be a fuzzy subgroup of a group G. For $a$ and $b$ in $G$, the fuzzy middle coset $a \mu b$ of $G$ is defined by $(a \mu b)(x)=\mu\left(a^{-1} x^{-1}\right)$ for all $x$ in $G$.

Definition 1.1.5: Let $\mu$ be a fuzzy subgroup of group $\mathrm{G}$ and an element a in $\mathrm{G}$. Then pseudo fuzzy coset $(a \mu)^{\mathrm{p}}$ is defined by $(a \mu)^{p}(x)=p(a) \mu(x)$ for all $x$ in $G$ and $p$ in $P$.

Definition 1.1.6: Let $\mu$ and $\lambda$ be any two fuzzy subsets of a set $\mathrm{X}$ and $\mathrm{p}$ in $\mathrm{P}$. then the pseudo fuzzy double coset $(\mu \mathrm{x} \lambda)^{\mathrm{p}}$ is defined by $(\mu x \lambda)^{p}=(x \mu)^{p} \cap(x \lambda)^{p}$ for every $x$ in $X$.

Definition 1.1.7: Let $\mu$ and $\lambda$ be any two fuzzy subsets of a set $X$. then

(i) $\quad \lambda$ and $\mu$ are equal if $\mu(x)=\lambda(x)$ for every $\mathrm{x}$ in $\mathrm{X}$

(ii) $\quad \lambda$ and $\mu$ are disjoint if $\mu(\mathrm{x}) \neq \lambda(\mathrm{x})$ for every $\mathrm{x}$ in $\mathrm{X}$ (iii) $\quad \lambda \subseteq \mu$ if $\mu(\mathrm{x}) \geq \lambda(\mathrm{x})$

Definition 1.1.8: Let $\mu$ be a fuzzy subset of a set $\mathrm{X}$. The collection $\xi=\left\{\mu_{\mathrm{i}}: \mu_{\mathrm{i}}\right.$ is a fuzzy subset of $X$ and $\mu_{\mathrm{i}}(\mathrm{x}) \leq \mu(\mathrm{x})$ for all $\mathrm{x}$ in $\mathrm{X}\}$ is a fuzzy partition of $\mu$ if

(i) $\quad \cup \mu_{\mathrm{i}}=\mu$ and

(ii) Any two members of $\xi$ are either disjoint or identical

Remark 1.1.8.1: Definition 1.1.7 gives the inequality $\mu_{1}<\mu_{2}<$ $\mu_{3}<\ldots<\mu_{\mathrm{j}}$ where $\mathrm{j}=|\xi|$. We can also infer that either $\mu_{\mathrm{i}}=\mu_{\mathrm{j}}$ or $\mu_{\mathrm{i}}<\mu_{\mathrm{j}}$ if $\mathrm{i} \neq \mathrm{j}$.

Definition 1.1.9: Let $\mu$ be a fuzzy subset (subgroup) of $\mathrm{X}$. Then, for some $t$ in $[0,1]$, the set $\mu_{t}=\{x$ in $X: \mu(x) \geq t\}$ is called a level subset (subgroup) of the fuzzy subset (subgroup) $\mu$.

Remark 1.1.9.1: the set $\mu_{\mathrm{t}}$ if it is group can be represented as $\mathrm{G}_{\mu}^{\mathrm{t}}$

Definition 1.1.10: Let $\mu$ be a fuzzy subgroup of a group G. The set $\mathrm{H}=\{\mathrm{x}$ in $\mathrm{G}: \mu(\mathrm{x})=\mu(\mathrm{e})\}$ is such that $\mathrm{o}(\mu)=\mathrm{o}(\mathrm{H})$.

Definition 1.1.11: Let $\mu$ be a fuzzy subgroup of a group $G$. $\mu$ is said to be normal if $\sup \mu(\mathrm{x})=1$ for all $\mathrm{x}$ in $G$. It is said to be normalized if there is an $\mathrm{x}$ in $G$ such that $\mu(\mathrm{x})=1$.

Theorem 1.1.12: A fuzzy subset $\mu$ of the group $\mathrm{G}$ is a fuzzy subgroup of $\mathrm{G}$ if and only if $\mu\left(\mathrm{xy}^{-1}\right) \geq \min \{\mu(\mathrm{x}), \mu(\mathrm{y})\}$.

Proposition 1.1.13: A fuzzy subset $\mu$ of a group $\mathrm{G}$ is a fuzzy subgroup of $\mathrm{G}$ if and only if $\mu\left(\mathrm{xy}^{-1}\right) \geq \min \{\mu(\mathrm{x}), \mu(\mathrm{y})\}$

\section{FUZZY SUBGROUPS}

\subsection{Proofs of Some Results}

Proposition 2.1.1: Let $\mathrm{G}$ be a group and $\mu$ a fuzzy subgroup of G. Then the level subgroup $\mu_{\mathrm{t}}$ is a subgroup of $\mathrm{G}$, with $\mu(\mathrm{e}) \geq \mathrm{t}$ in $[0,1]$ and $\mathrm{e}$ is the identity of $\mathrm{G}$.

Proof: Since $\mathrm{G}$ is a group, $\mathrm{g}, \mathrm{g}^{-1}, \mathrm{e} \in \mathrm{G}$, the equation $\mathrm{e}=\mathrm{gg}^{-1}$ is true. Note that $\mu_{\mathrm{t}}$ is not empty since $\mu(\mathrm{e}) \geq \mathrm{t}$. Let $\mathrm{g}, \mathrm{g}^{-1}$, be in $\mu_{\mathrm{t}}$. See that $\mu\left(\mathrm{gg}^{-1}\right)=\mu(\mathrm{e})$. Then $\mu(\mathrm{e})=\mu\left(\mathrm{gg}^{-1}\right) \geq \min \{\mu(\mathrm{g})$, $\left.\mu\left(\mathrm{g}^{-1}\right)\right\} \geq \mathrm{t}$ since both $\mathrm{g}$ and $\mathrm{g}^{-1}$ are in $\mu_{\mathrm{t}}$. Then, $\mu\left(\mathrm{gg}^{-1}\right) \geq \mathrm{t}$. Thus, the product $\mathrm{gg}^{-1}$ is in $\mu_{\mathrm{t}}$. Hence $\mu_{\mathrm{t}}$ is a subgroup of $\mathrm{G}$.

Proposition 2.1.2: Let $\mathrm{G}$ be a group and $\mu$ a fuzzy subset ofG. Then $\mu$ is a fuzzy subgroup of $G$ and only if $G_{\mu}^{t}$ is a level subgroup of $\mathrm{G}$ for every $\mathrm{t}$ in $[0, \mu(\mathrm{e})]$, where e is the identity of G.

Proof: Assume that $\mu$ is a fuzzy subgroup of G. Then any $x, y$ in $G_{\mu}^{t}$ is such that $x, y$ in $G$. Hence, $\mu(x y) \geq$ $\min \{\mu(\mathrm{x}), \mu(\mathrm{y})\} \geq \mathrm{t}$ and $\mu\left(\mathrm{y}^{-1}\right)=\mu(\mathrm{y})$. If we let $\mathrm{x}, \mathrm{y}^{-1}$ be in $\mathrm{G}_{\mu}^{\mathrm{t}}$ then they are also in G. So $\mu\left(x^{-1}\right) \geq \min \left\{\mu(x), \mu\left(y^{-1}\right)\right\} \geq t$. Then, $\mathrm{xy}^{-1}$ is in $\mathrm{G}_{\mu}^{\mathrm{t}}$. $\mathrm{G}_{\mu}^{\mathrm{t}}$ is a subgroup of $G$. By 2.1, $0 \leq \mathrm{t} \leq \mu(e)$. Hence, $\mathrm{G}_{\mu}^{\mathrm{t}}$ is a group for all $\mathrm{t} \in[0, \mu(e)]$. 
Conversely, assume $G_{\mu}^{t}$ is a subgroup of $G$ for all $t$ in $[0, \mu(\mathrm{e})]$. Then, for any $\mathrm{x}, \mathrm{y}$ is in $\mathrm{G}_{\mu}^{\mathrm{t}}$, xy is also in $\mathrm{G}_{\mu}^{\mathrm{t}}$. Hence, $\mu(\mathrm{e})=\mu\left(\mathrm{xx}^{-1}\right) \geq \min \left\{\mu(\mathrm{x}), \mu\left(\mathrm{x}^{-1}\right)\right\}=\mu(\mathrm{x})$ or $\mu\left(\mathrm{x}^{-1}\right)$. If $\min \left\{\mu(\mathrm{x}), \mu\left(\mathrm{x}^{-1}\right)\right\}=\mu(\mathrm{x})$ and choosing $\mathrm{x}=\mathrm{y}, \mu\left(\mathrm{xy}^{-1}\right) \geq$ $\min \{\mu(\mathrm{x}), \mu(\mathrm{x})\} \geq \min \{\mu(\mathrm{x}), \mu(\mathrm{y})\}$. Or if $\mu\left(\mathrm{xx}^{-1}\right) \geq \min \{\mu(\mathrm{x})$, $\left.\mu\left(x^{-1}\right)\right\}=\mu\left(x^{-1}\right)=\min \left\{\mu\left(x^{-1}\right), \mu\left(x^{-1}\right)\right\}$. If $y=x^{-1}$ is chosen and $\mathrm{y}^{-1}=\left(\mathrm{x}^{-1}\right)^{-1}, \mu\left(\mathrm{xy}^{-1}\right) \geq \min \left\{\mu(\mathrm{x}), \mu\left(\left(\mathrm{x}^{-1}\right)^{-1}\right)\right\}=\min \{\mu(\mathrm{x}), \mu((\mathrm{x})\}$ $\geq \min \left\{\mu(\mathrm{x}), \mu\left(\mathrm{x}^{-1}\right)\right\}=\min \{\mu(\mathrm{x}), \mu(\mathrm{y})\}$. Then the inequality $\mu\left(x y^{-1}\right) \geq \min \{\mu(x), \mu(y)\}$ holds. In both cases, apply 1.12. So, $\mu$ is a fuzzy subgroup of $\mathrm{G}$.

Proposition 2.1.3: Let $\mu$ be a fuzzy subgroup of a group $\mathrm{G}$ and $\mathrm{x}$ in $\mathrm{G}$. Then $\mu(\mathrm{xy})=\mu(\mathrm{y})$ for every $\mathrm{y}$ in $\mathrm{G}$ if and only if $\mu(\mathrm{x})$ $=\mu(\mathrm{e})$.

Proof: Assume $\mu(x y)=\mu(y)$. Since $G$ is a group, $g, g^{-1}$, e in $G$ and the equation $\mathrm{e}=\mathrm{gg}^{-1}$ is true for $\mathrm{e}$ in $\mathrm{G}$. Also associativity holds in $G$ such have that $\mu\left((x y) y^{-1}\right)=\mu\left(y^{-1}\right)$ implies that $\mu\left(x\left(y^{-1}\right)\right)=\mu\left(y^{-1}\right)$ which also implies that $\mu(x e)=\mu(x)=$ $\mu(\mathrm{e})$.

Conversely, assume $\mu(\mathrm{x})=\mu(\mathrm{e})$. Let $\mathrm{y}$ and $\mathrm{y}^{-1}$ be in $\mathrm{G} . \mu(\mathrm{x})=$ $\mu(\mathrm{e})$ implies the following: $\mu\left((x y) y^{-1}\right)=\mu(e), \mu\left((x y) y^{-1}\right)=$ $\mu(\mathrm{e}), \mu\left((\mathrm{xy}) \mathrm{y}^{-1} \mathrm{y}\right)=\mu(\mathrm{ey})$ and $\mu(\mathrm{xy})=\mu(\mathrm{y})$.

Proposition 2.1.4: $\mathrm{H}$ as described in 1.1 .10 can be realized as a level subgroup.

Proposition 2.1.5: Let $\mu$ be an improper (i.e. constant) fuzzy subgroup of $\mathrm{G}$. Then the order of $\mathrm{o}(\mathrm{G})=\mathrm{o}(\mu)$.

Proof: The set $\mathrm{H}=\{\mathrm{x}$ in $\mathrm{G}: \mu(\mathrm{x})=\mu(\mathrm{e})\}$ is such that $\mathrm{o}(\mu)=$ $\mathrm{o}(\mathrm{H})$. But $\mu$ is constant on $\mathrm{G}$ so that for all $\mathrm{x}$ in $\mathrm{G}, \mu(\mathrm{x})$ is say t. But $\mathrm{e}$ is also in $\mathrm{G}$. Then $\mu(\mathrm{e})=\mu(\mathrm{x})=\mathrm{t}$. The set $\mathrm{H}=\mathrm{G}$ so that $\mathrm{o}(\mu)=\mathrm{o}(\mathrm{H})=\mathrm{o}(\mathrm{G})$

Proposition 2.1.6: Let $\mathrm{G}$ be a finite group of order $\mathrm{n}$ and $\mu$ a fuzzy subgroup of $\mathrm{G}$. The following are equivalent:
(i) $\quad \mathrm{G}$ is cyclic
(ii) $\quad \mathrm{o}(\mu)=1$
(iii) The only level subgroup of $\mathrm{G}$ is trivial

Proof: Assume $G$ is cyclic. $G=\left\{a^{m}: m\right.$ in $\left.Z\right\}$. Since $G$ is of order $\mathrm{n},\left(\mathrm{a}^{\mathrm{m}}\right)^{\mathrm{n}}=\mathrm{e}$. This element in $\mathrm{G}$ is unique. So $\mathrm{H}=\{\mathrm{e}\}$ and $\mathrm{o}(\mu)=\mathrm{o}(\mathrm{H})=1$

Assume $o(\mu)=1$. H which is a level subgroup of $\mathrm{G}$ by 2.1.4 has just one element. This is the group $\{\mathrm{e}\}$.

Assume that $\mathrm{G}$ has only one level subgroup $\{\mathrm{e}\}$. Then $\mathrm{a}^{\mathrm{mn}}=\mathrm{e}$ for some $\mathrm{m}, \mathrm{n}$ in $\mathrm{Z}$. So $\mathrm{G}=\left\{\mathrm{a}^{1}, \mathrm{a}^{2}, \mathrm{a}^{3}, \ldots, \mathrm{a}^{\mathrm{mn}}=\mathrm{e}\right\}$. Hence, $\mathrm{a}^{\mathrm{m}}$ generates $G$ so that $G=\left\{a^{m}: m\right.$ in $\left.Z\right\}$.

Proposition 2.1.7: The group $\mathrm{G}$ is abelian if and only if every fuzzy subgroup of $\mathrm{G}$ is normal.

Proof: If $\mathrm{G}$ is abelian, $\mathrm{xy}=\mathrm{yx}$ for every $\mathrm{x}$ and $\mathrm{y}$ in $\mathrm{G}$. Obviously, for any fuzzy subgroup $\mu$ of $G, \mu(x y)=\mu(y x)$. This means $\mu$ is a fuzzy normal subgroup.

Conversely, let any $\mu$ of $\mathrm{G}$ be a fuzzy normal subgroup, then $\mu(\mathrm{xy})=\mu(\mathrm{yx})$ which implies that $\mathrm{xy}=\mathrm{yx}$ for all $\mathrm{x}$ and $\mathrm{y}$ in $\mathrm{G}$. $\mathrm{G}$ is abelian.

\section{FUZZY COSETS}

\subsection{Independent Proofs of Some Results On Fuzzy Cosets}

Proposition 3.1.1: Let $\mu$ be a fuzzy subgroup of a group $G$. Then $\mathrm{aG}_{\mu}^{\mathrm{t}}=\mathrm{G}_{\mathrm{a \mu}}^{\mathrm{t}}$ for every a in $G$ and $\mathrm{t}$ in $[0, \mu(\mathrm{e})]$.
Proof: By 2.1.2, $\mathrm{G}_{\mu}^{\mathrm{t}}$ is a subgroup of $\mathrm{G}$. Let $\mathrm{aG}_{\mu}^{\mathrm{t}}=\left\{\mathrm{ax}: \mathrm{x}\right.$ is in $\left.\mathrm{G}_{\mu}^{\mathrm{t}}\right\}$. Then, $\mathrm{aG}_{\mu}^{\mathrm{t}}$ is a left coset in $\mathrm{G}$ containing a so that $\mathrm{aG}_{\mu}^{\mathrm{t}}$ is a partition of $\mathrm{G}$ into its level subgroups. Also, define $\mathrm{G}_{\mathrm{a} \mu}^{\mathrm{t}}=\left\{\mathrm{x}\right.$ in $\left.\mathrm{G}:(\mathrm{a} \mu)(\mathrm{x})=\mu\left(\mathrm{a}^{-1}\right) \geq \mathrm{t}\right\}$. Then $\mu\left(a^{-1} \mathrm{x}\right) \geq \min \left\{\mu\left(\mathrm{a}^{-1}\right), \mu(\mathrm{x})\right\} \geq \mathrm{t}$. Then $\mathrm{x}$ and $\mathrm{a}^{-1}$ belong to a level subgroup of $\mathrm{G}$. That level subgroup also contains a since it contains $\mathrm{a}^{-1}$. But $\mathrm{G}$ is partitioned into level subgroups so that if both $\mathrm{G}_{\mathrm{a} \mu}^{\mathrm{t}}$ and $\mathrm{aG}_{\mu}^{\mathrm{t}}$ are level subgroups which contain a, then they are the same class.

Proposition 3.1.2: Let $\mu$ be a fuzzy subgroup of a group G. Then, the pseudo fuzzy coset $(a \mu)^{\mathrm{p}}$ is a fuzzy subgroup of $\mathrm{G}$.

Lemma 3.1.3: All left cosets of a subgroup $\mathrm{H}$ of a group $\mathrm{G}$ have the same order.

Proposition 3.1.4: Let $\mu$ be a fuzzy subgroup of a finite group $\mathrm{G}$ and $\mathrm{t}$ in $[0,1]$. Then $\mathrm{o}\left(\mathrm{G}_{(\mathrm{a} \mu) \mathrm{p}}^{\mathrm{t}}\right) \leq \mathrm{o}\left(\mathrm{G}_{\mu}^{\mathrm{t}}\right)=\mathrm{o}\left(\mathrm{a} \mathrm{G}_{\mu}^{\mathrm{t}}\right)$.

Proof: Define $\mathrm{G}_{(\mathrm{a} \mu) \mathrm{p}}^{\mathrm{t}}=\left\{\mathrm{x}\right.$ in $\left.\mathrm{G}:(\mathrm{a} \mu)^{\mathrm{p}}(\mathrm{x})=\mathrm{p}(\mathrm{a}) \mu(\mathrm{x}) \geq \mathrm{t}\right\}$ and $\mathrm{G}_{\mu}^{\mathrm{t}}=\{\mathrm{x}$ in $\mathrm{G}: \mu(\mathrm{x}) \geq \mathrm{t}\}$. Note that $0 \leq \mathrm{p}(\mathrm{a}) \leq 1$ since $(a \mu)^{\mathrm{p}}(\mathrm{x})$ is a fuzzy subgroup of $G$ by 3.1.2. Then, $\mu(x) \geq p(a) \mu(x) \geq t$. Thus $(a \mu)^{\mathrm{p}}(\mathrm{x}) \leq \mu(\mathrm{x})$ and $(\mathrm{a} \mu)^{\mathrm{p}} \subseteq \mu$. Then, $\mathrm{o}\left(\mathrm{G}_{(\mathrm{a} \mu) \mathrm{p}}^{\mathrm{t}}\right) \leq \mathrm{o}\left(\mathrm{G}_{\mu}^{\mathrm{t}}\right)$.

Furthermore, define $\mathrm{aG}_{\mu}^{\mathrm{t}}=\left\{\right.$ ax: $\mathrm{x}$ in $\mathrm{G}_{\mu}^{\mathrm{t}}$ and $\left.\mu(\mathrm{x}) \geq \mathrm{t}\right\}$. By 2.1.2, $\mathrm{G}_{\mu}^{\mathrm{t}}$ is a subgroup of $\mathrm{G}$. Then, $\mathrm{aG}_{\mu}^{\mathrm{t}}$ is a left coset of $\mathrm{G}$. By 3.1.3, o $\left(\mathrm{G}_{\mu}^{\mathrm{t}}\right)=\mathrm{o}\left(\mathrm{aG}_{\mu}^{\mathrm{t}}\right)$. Hence, $\mathrm{o}\left(\mathrm{G}_{(\mathrm{a \mu}) \mathrm{p}}^{\mathrm{t}}\right) \leq \mathrm{o}\left(\mathrm{G}_{\mu}^{\mathrm{t}}\right)=$ $\mathrm{o}\left(\mathrm{aG}_{\mu}^{\mathrm{t}}\right)$.

\section{PSEUDO FUZZY COSET}

\subsection{Proofs of Some Fundamental Results}

Proposition 4.1.1: Any two pseudo cosets of a fuzzy subgroup of a group $\mathrm{G}$ are either identical or disjoint.

Proof: Assume that $(\mathrm{a} \mu)^{\mathrm{p}}$ and $(\mathrm{b} \mu)^{\mathrm{p}}$ are any two identical pseudo fuzzy cosets of $\mu$ for any $a$ and $b$ in $G$. Then, $(\mathrm{a} \mu)^{\mathrm{p}}(\mathrm{x})=(\mathrm{b} \mu)^{\mathrm{p}}(\mathrm{x})$ for all $\mathrm{x}$ in G. Assume also on the contrary that they are disjoint. Then, there is no $y$ in $G$ such that $(\mathrm{a} \mu)^{\mathrm{p}}(\mathrm{y})=(\mathrm{b} \mu)^{\mathrm{p}}(\mathrm{y})$ which implies that $\mathrm{p}(\mathrm{a}) \mu(\mathrm{y}) \neq \mathrm{p}(\mathrm{b}) \mu(\mathrm{y})$. The consequence is that $\mathrm{p}(\mathrm{a}) \neq \mathrm{p}(\mathrm{b})$. This makes the assumption $(\mathrm{a} \mu)^{\mathrm{p}}(\mathrm{x})=(\mathrm{b} \mu)^{\mathrm{p}}(\mathrm{x})$ false.

Conversely, assume that $(a \mu)^{\mathrm{p}}$ and $(b \mu)^{\mathrm{p}}$ are disjoint, then $\mathrm{p}(\mathrm{a}) \mu(\mathrm{y}) \neq \mathrm{p}(\mathrm{b}) \mu(\mathrm{y})$ for every $\mathrm{y}$ in G. But if it is assumed that this is also identical, then $\mathrm{p}(\mathrm{a}) \mu(\mathrm{y})=\mathrm{p}(\mathrm{b}) \mu(\mathrm{y})$ and that means $\mathrm{p}(\mathrm{a})=\mathrm{p}(\mathrm{b})$ so that $\mathrm{p}(\mathrm{a}) \mu(\mathrm{y}) \neq \mathrm{p}(\mathrm{b}) \mu(\mathrm{y})$ cannot be true.

Proposition 4.1.2: Let $\lambda$ and $\mu$ be any two fuzzy subsets of a set $G$. Then for a in $G(a \mu)^{p}$ is contained in $(a \lambda)^{p}$ not in the strict sense if and only if $\mu$ is also contained in $\lambda$ not in the strict sense.

Proof: Assume that $(\mathrm{a} \mu)^{\mathrm{p}}$ is contained in $(\mathrm{a} \lambda)^{\mathrm{p}}$. Then $(a \mu)^{\mathrm{p}}(\mathrm{x}) \leq(\mathrm{a} \lambda)^{\mathrm{p}}(\mathrm{x})$. Thus, $\mathrm{p}(\mathrm{a}) \mu(\mathrm{x}) \leq \mathrm{p}(\mathrm{a}) \lambda(\mathrm{x})$. This means that $\mu(\mathrm{x})$ is contained in $\lambda(\mathrm{x})$ not in a strict sense using definition 1.1.7 (iii).

Assume also that $\mu$ is contained in $\lambda$ not in the strict sense. Then $\mu(\mathrm{x}) \leq \lambda(\mathrm{x})$, which implies that $\mathrm{p}(\mathrm{a}) \mu(\mathrm{x}) \leq \mathrm{p}(\mathrm{a}) \lambda(\mathrm{x})$. Hence, $(a \mu)^{p}$ is contained in $(a \lambda)^{p}$ not in the strict sense.

Proposition 4.1.3: Let $\mu$ be a positive fuzzy subset of a set $\mathrm{X}$ then

(i) Any two pseudo cosets of $\mu$ are either identical or disjoint.

(iii) $\quad \mathrm{U}_{\mathrm{x} \text { in } \mathrm{X}}\left\{(\mathrm{a} \mu)^{\mathrm{p}}\right\}=\mathrm{U}_{\mathrm{p} \text { in } \mathrm{P}}\left\{(\mathrm{a} \mu)^{\mathrm{p}}\right\}$ if and only if $\mathrm{p}$ is normal. 
(iv) The collection $\left\{(\mathrm{a} \mu)^{\mathrm{p}}: \mathrm{a}\right.$ in $\left.\mathrm{X}\right\}$ is a fuzzy partition of $\mu$ if and only if $p$ is normal.

Proof: By 4.1.1, (i) is true.

(ii), $\mathrm{p}(\mathrm{a}) \mu(\mathrm{x}) \leq \mu(\mathrm{x})$. Then $(\mathrm{a} \mu)^{\mathrm{p}}(\mathrm{x}) \leq \mu(\mathrm{x})$. Without loss of any generality, $\mathrm{U}_{\mathrm{p} \text { in } \mathrm{P}}(\mathrm{a} \mu)^{\mathrm{p}}(\mathrm{x}) \leq \mu(\mathrm{x})$. Thus $\mathrm{U}_{\mathrm{p} \text { in } \mathrm{P}}(\mathrm{a} \mu)^{\mathrm{p}}(\mathrm{x}) \subseteq \mu(\mathrm{x})$ by 1.1 .7

(iii) Since $p$ is normal, there is an a in $X$ such that $p(a)=1$ so that such $\mathrm{p}(\mathrm{a}) \mu(\mathrm{x})=\mu(\mathrm{x})$ shows that $\sup (\mathrm{a} \mu)(\mathrm{x})=\mu(\mathrm{x})$. Then $\mu(\mathrm{x}) \subseteq \mathrm{U}_{\mathrm{p} \text { in } \mathrm{P}}(\mathrm{a} \mu)^{\mathrm{p}}(\mathrm{x})$. These two set inclusions give that $U_{\mathrm{p} \text { in } \mathrm{P}}\left\{(\mathrm{a} \mu)^{\mathrm{p}}\right\}=\mu$.

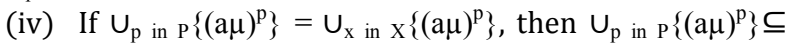
$\mathrm{U}_{\mathrm{x}}$ in $\mathrm{X}\left\{(\mathrm{a} \mu)^{\mathrm{p}}\right\}$. Then for a $\mathrm{p}$ in $\mathrm{P},(\mathrm{a} \mu)^{\mathrm{p}} \subseteq \mathrm{U}_{\mathrm{x}}$ in $\mathrm{X}\left\{(\mathrm{a} \mu)^{\mathrm{p}}\right\}$. Then $\mathrm{p}(\mathrm{a}) \mu(\mathrm{x}) \leq \mathrm{p}(\mathrm{a}) \mu(\mathrm{x}) \leq \mu(\mathrm{x})$ for all a in $\mathrm{X}$. Then there is an $\mathrm{a}$ in $X$ such that $\mathrm{p}(\mathrm{a})=1$ for which $\mathrm{p}(\mathrm{a}) \mu(\mathrm{x}) \leq \mu(\mathrm{x})$ for any a or any $p$. Hence $p$ is normal.

Conversely, if $\mathrm{p}$ is normal, there is an a in $\mathrm{X}$ such that $\mathrm{p}(\mathrm{a})=1$ for which $\mathrm{p}(\mathrm{b}) \mu(\mathrm{x}) \leq \mathrm{p}(\mathrm{a}) \mu(\mathrm{x})=\mu(\mathrm{x})$.

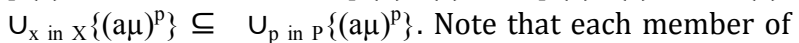

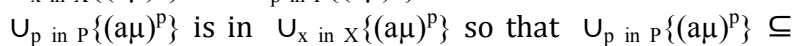
$\mathrm{U}_{\mathrm{x} \text { in } \mathrm{X}}\left\{(\mathrm{a} \mu)^{\mathrm{p}}\right\}$.

For (iv) Assume $\left\{(\mathrm{a} \mu)^{\mathrm{p}} \mathrm{a}\right.$ a in $\left.\mathrm{X}\right\}$ is a partition of $\mu$.

$\mathrm{U}(\mathrm{a} \mu)^{\mathrm{p}}=\mu$ and $(\mathrm{a} \mu)^{\mathrm{p}} \neq(\mathrm{b} \mu)^{\mathrm{p}}$ if $\mathrm{a} \neq \mathrm{b}$. By the assumption that $\mathrm{U}(\mathrm{a} \mu)^{\mathrm{p}}=\mu$, we have $\mathrm{U}(\mathrm{a} \mu)^{\mathrm{p}} \subseteq \mu$. Hence, each of $(\mathrm{a} \mu)^{\mathrm{p}} \leq \mu$. Also from the assumption $\mu$ is also in $U(a \mu)^{p}$ so that $\mu$ is strictly greater than any of $(a \mu)^{\mathrm{p}}$ since any two elements in $\mathrm{U}(\mathrm{a} \mu)^{\mathrm{p}}$ are either identical or disjoint. Then, $(\mathrm{a} \mu)^{\mathrm{p}}(\mathrm{x})<\mu(\mathrm{x})$. Hence there is an $a$ in $X$ such that $p(a)=1$ and $(\mathrm{a} \mu)^{\mathrm{p}}(\mathrm{x})<\mathrm{p}(\mathrm{a}) \mu(\mathrm{x})=\mu(\mathrm{x})$. Hence $\mathrm{p}$ is normal. Conversely, assume that $\mathrm{p}$ is normal, $\sup \mathrm{p}(\mathrm{a})=1$. Let $\mathrm{p}(\mathrm{b})=1$. $\mu(\mathrm{x})=\mathrm{p}(\mathrm{b}) \mu(\mathrm{x})$ in $U(\mathrm{a} \mu)^{\mathrm{p}}$. This implies that $\mu(\mathrm{x}) \leq(\mathrm{a} \mu)^{\mathrm{p}}$ so that $\mu \subseteq(\mathrm{a} \mu)^{\mathrm{p}} \subseteq \mathrm{U}(\mathrm{a} \mu)^{\mathrm{p}}$. Usually, $\mathrm{p}(\mathrm{a}) \mu(\mathrm{x}) \leq \mu(\mathrm{x})$. This implies that $U(\mathrm{a} \mu)^{\mathrm{p}} \subseteq \mu$. These inclusions show that $\mathrm{v}(\mathrm{a} \mu)^{\mathrm{p}}=\mu$.

Proposition 4.1.4: Let $\mu$ and $\lambda$ be any two fuzzy subsets of $\mathrm{X}$. Then for a in $\mathrm{X},(\mathrm{a} \mu)^{\mathrm{p}} \subseteq(\mathrm{a} \lambda)^{\mathrm{p}}$ if and only if $\mu \subseteq \lambda$.

Proof: Assume $(\mathrm{a} \mu)^{\mathrm{p}} \subseteq(\mathrm{a} \lambda)^{\mathrm{p}}$. Then for any $\mathrm{x}$ in $\mathrm{X}$, $(a \mu) \mathrm{p}(\mathrm{x}) \leq(\mathrm{a} \lambda)^{\mathrm{p}}(\mathrm{x})$ which implies that $\mathrm{p}(\mathrm{a}) \mu(\mathrm{x}) \leq \mathrm{p}(\mathrm{a}) \lambda(\mathrm{x})$. Hence, $\mu(\mathrm{x}) \leq \lambda(\mathrm{x})$. In which case $\mu \subseteq \lambda$.

Conversely, assume $\mu \subseteq \lambda$, then $\mu(\mathrm{x}) \leq \lambda(\mathrm{x})$ which also implies $\mathrm{p}(\mathrm{a}) \mu(\mathrm{x}) \leq \mathrm{p}(\mathrm{a}) \lambda(\mathrm{x})$. Thus, $(\mathrm{a} \mu)^{\mathrm{p}}(\mathrm{x}) \leq(\mathrm{a} \lambda)^{\mathrm{p}}(\mathrm{x})$, meaning that $(\mathrm{a} \mu)^{\mathrm{p}} \subseteq(\mathrm{a} \lambda)^{\mathrm{p}}$.

Proposition 4.1.5: Let $\mu$ be a fuzzy subgroup of any group $G$. Let $\left\{\mu_{\mathrm{i}}\right\}$ be a partition of $\mu$. Then

(i) each $\mu_{\mathrm{i}}$ is normal if $\mu$ is normalized

(ii) each $\mu_{\mathrm{i}}$ is normal if $\mu$ is normal.
Proof: Note that for each $i \mu_{\mathrm{i}} \subseteq \mu$ which implies that $\mu_{\mathrm{i}}(\mathrm{x}) \leq$ $\mu(x)$ for all $x$ in G. (i) Since $\mu$ is normalized, there is an $x_{0}$ in G such that $\mu_{\mathrm{i}}\left(\mathrm{x}_{\mathrm{o}}\right) \leq \mu(\mathrm{x}) \leq \mu\left(\mathrm{x}_{\mathrm{o}}\right)=1$ for each $i$. Then $\mu_{\mathrm{i}}\left(\mathrm{x}_{\mathrm{o}}\right) \leq 1$. Then sup $\mu_{\mathrm{i}}\left(\mathrm{x}_{\mathrm{o}}\right)=1$. (ii) Since $\mu$ is normal, $\sup \mu(\mathrm{x})=1$, then $\mu(\mathrm{x}) \leq 1$. But $\mu_{\mathrm{i}}(\mathrm{x}) \leq \mu(\mathrm{x}) \leq 1$. Then, $\mu_{\mathrm{i}}\left(\mathrm{x}_{\mathrm{o}}\right) \leq 1$ and $\sup \mu_{\mathrm{i}}\left(\mathrm{x}_{\mathrm{o}}\right)=1$.

\section{Pseudo Fuzzy Double Coset}

\subsection{Independent Proofs}

Proposition 5.1.1: Let $\mu$ and $\lambda$ be any two fuzzy subsets of a set $\mathrm{X}$ and $\mathrm{p}$ in $\mathrm{P}$. The set of all pseudo fuzzy double coset $\left\{(\lambda x \mu)^{p}: x\right.$ in $\left.X\right\}$ is a partition of $(\lambda \cap \mu)$ if and only if $p$ is normal.

Proof: Assume that the set $\left\{\left(\lambda \mathrm{x}_{\mathrm{i}} \mu\right)^{\mathrm{p}}: \mathrm{x}\right.$ in $\left.\mathrm{X}\right\}$ is a partition of $(\lambda \cap \mu)$. Then any two members are either identical or disjoint. By the equality $\lambda \cap \mu=U\left(\lambda \mathrm{x}_{\mathrm{i}} \mu\right)^{\mathrm{p}}, \mathrm{U}(\lambda \mathrm{x} \mu)^{\mathrm{p}} \subseteq \lambda \cap \mu$ holds. Hence the chain $\left(\lambda \mathrm{x}_{1} \mu\right)^{\mathrm{p}}<\left(\lambda \mathrm{x}_{2} \mu\right)^{\mathrm{p}}<\left(\lambda \mathrm{x}_{3} \mu\right)^{\mathrm{p}}<\ldots<\lambda \cap \mu$ holds. This yields $\left(\mathrm{x}_{1} \lambda\right)^{\mathrm{p}} \cap\left(\mathrm{x}_{1} \mu\right)^{\mathrm{p}}<\left(\mathrm{x}_{2} \lambda\right)^{\mathrm{p}} \cap\left(\mathrm{x}_{2} \mu\right)^{\mathrm{p}}<\left(\mathrm{x}_{3} \lambda\right)^{\mathrm{p}} \cap\left(\mathrm{x}_{3} \mu\right)^{\mathrm{p}}$ $<\ldots<\lambda \cap \mu=\min \{\lambda, \mu\}$. This in turn yields $\min \left\{\mathrm{p}\left(\mathrm{x}_{1}\right) \lambda, \quad \mathrm{p}\left(\mathrm{x}_{1}\right) \mu\right\}<\min \left\{\mathrm{p}\left(\mathrm{x}_{2}\right) \lambda, \quad \mathrm{p}\left(\mathrm{x}_{2}\right) \mu\right\}<$ $\min \left\{\mathrm{p}\left(\mathrm{x}_{3}\right) \lambda, \mathrm{p}\left(\mathrm{x}_{3}\right) \mu\right\}<\ldots<\min \{\lambda, \mu\}$. Then, $\mathrm{p}\left(\mathrm{x}_{1}\right) \min \{\lambda, \mu\}<$ $\mathrm{p}\left(\mathrm{x}_{2}\right) \min \{\lambda, \mu\}<\mathrm{p}\left(\mathrm{x}_{3}\right) \min \{\lambda, \mu\}<\ldots<\min \{\lambda, \mu\}$. Hence, $\mathrm{p}\left(\mathrm{x}_{1}\right)<\mathrm{p}\left(\mathrm{x}_{2}\right)<\mathrm{p}\left(\mathrm{x}_{3}\right)<\ldots<1$. Then there is an $\mathrm{x}_{0}$ in $\mathrm{X}$ so that $\mathrm{p}\left(\mathrm{x}_{\mathrm{o}}\right)=1$ and $\mathrm{p}\left(\mathrm{x}_{1}\right)<\mathrm{p}\left(\mathrm{x}_{2}\right)<\mathrm{p}\left(\mathrm{x}_{3}\right)<\ldots \mathrm{p}(\mathrm{x})=1$. Then $\mathrm{p}(\mathrm{x}) \leq 1$ and $\operatorname{Sup} \mathrm{p}(\mathrm{x})=1$. Then $\mathrm{p}$ is normal.

Conversely, if $\mathrm{p}$ is normal, then $\mathrm{x}_{0}$ is in $\mathrm{X}$ such that $\mathrm{p}(\mathrm{x}) \leq \mathrm{p}\left(\mathrm{x}_{\mathrm{o}}\right)=1$. Then $\left(\lambda \mathrm{x}_{\mathrm{i}} \mu\right)^{\mathrm{p}} \leq\left(\lambda \mathrm{x}_{0} \mu\right)^{\mathrm{p}}=\mathrm{p}\left(\mathrm{x}_{\mathrm{o}}\right) \lambda \cap \mathrm{p}\left(\mathrm{x}_{\mathrm{o}}\right) \mu=$ $\lambda \cap \mu$ for all i. Then $\mathrm{U}\left(\lambda \mathrm{x}_{\mathrm{i}} \mu\right)^{\mathrm{p}} \subseteq \lambda \cap \mu$. (*). $\mathrm{p}\left(\mathrm{x}_{\mathrm{o}}\right) \lambda \cap \mathrm{p}\left(\mathrm{x}_{\mathrm{o}}\right) \mu=$ $\left(\lambda \mathrm{x}_{0} \mu\right)^{\mathrm{p}} \subseteq \mathrm{U}(\lambda \mathrm{x} \mu)^{\mathrm{p}}(* *)$. (*) and $(* *)$ show that $\lambda \cap \mu=$ $\mathrm{U}(\lambda \mathrm{x} \mu)^{\mathrm{p}}$. Any $\left(\lambda \mathrm{x}_{\mathrm{i}} \mu\right)^{\mathrm{p}}=\left(\lambda \mathrm{x}_{\mathrm{j}} \mu\right)^{\mathrm{p}}$ for $\mathrm{i} \neq \mathrm{j}$ implies $\mathrm{p}\left(\mathrm{x}_{\mathrm{i}}\right)=\mathrm{p}\left(\mathrm{x}_{\mathrm{j}}\right)$. Hence no $\mathrm{y}$ in $\mathrm{X}$ so that $\left(\lambda \mathrm{x}_{\mathrm{i}} \mu\right)^{\mathrm{p}}(\mathrm{y})_{\neq}\left(\lambda \mathrm{x}_{\mathrm{j}} \mu\right)^{\mathrm{p}}(\mathrm{y})$. Thus, the set $\left\{\left(\lambda x_{i} \mu\right)^{p}: x\right.$ in $\left.X\right\}$ is either identical or disjoint.

\section{REFERENCES}

[1] A. O. Kuku, Abstract Algebra, Ibadan University Press, Nigeria (1992)

[2] F. E. Mohammed, Fuzzy Algebra, Doctoral Thesis, Faculty of Engineering, Fayoum University (2006)

[3] M. Artin, Algebra (Second Edition), PHI Learning Private Limited, New Delhi-110001 (2012)

[4] R. Nagarajan and A. Solairaju, On Pseudo Fuzzy Cosets of Fuzzy Normal Subgroups, IJCA (0975-8887), Volume 7, No 6, 34-37 (2010).

[5] S. Shuka, Pseudo Fuzzy Cosets, IJSRP, Volume 3, Issue 1, 1-2 (2013).

[6] W. B. Vasantha Kandasamy, Smarandache Fuzzy Algebra, American Research Press, Rehoboth (2003). 